\title{
Dipole Moment of Tetraborane
}

\author{
J. R. Weaver, C. W. Heitsch, and R. W. Parry \\ Department of Chemistry, University of Michigan, Ann Arbor, Michigan
}

(Received October 6, 1958)

The dipole moment of tetraborane, as measured in benzene solution by a heterodyne beat method, is $0.56 \pm 0.1$.

B Y a molecular orbital treatment of boron hydride structures using a three-center-bond approximation, Eberhardt, Crawford, and Lipscomb ${ }^{1}$ were able to rationalize the known dipole moment values of $2.13 \mathrm{D}$ for $\mathrm{B}_{5} \mathrm{H}_{9}{ }^{2}$ and $3.52 \mathrm{D}$ for $\mathrm{B}_{10} \mathrm{H}_{14} \cdot{ }^{3}$ Their treatment also predicted to a first approximation a zero dipole moment for $\mathrm{B}_{4} \mathrm{H}_{10}$ if the boron skeleton, without moments due to attached hydrogens, were considered. We have measured the dipole moment of tetraborane in benzene solution using a heterodyne beat method and have obtained the relatively small value of $0.56 \pm 0.1$ Debye unit. Chemical arguments suggest the possibility of slight protonic character in the bridge hydrogens and slight negative character in the hydrogens attached to the single-bonded borons. The dipole data are consistent with but do not prove such an assumption. Since the low B--H moments were neglected in the earlier theoretical treatment, the theoretical arguments are not in serious disagreement with the current dipole information.

\section{EXPERIMENTAL}

Tetraborane from laboratory stock was purified by low-temperature fractionation on the vacuum line. The purified product had a vapor pressure of $388 \pm 3 \mathrm{~mm}$ at $0^{\circ} \mathrm{C}$. When the sample was allowed to stand at $0^{\circ} \mathrm{C}$ for more than a few minutes, decomposition was indicated by a slow buildup in pressure.

Reagent-grade benzene was dried by refluxing with calcium hydride and distilling on the vacuum line.

Solutions were prepared by condensing benzene and a measured volume of tetraborane vapor into a special weighing cell. Transfer to the dielectric cell was made under an atmosphere of dry nitrogen, since it was considered undesirable to evacuate the cell because of damage to the silvered surfaces. The cell was of a conventional design ${ }^{4}$ with a capacitance of about $30 \mu \mu f$. The measuring circuit has been previously described. ${ }^{5}$ It was necessary to make the capacitance measurements rapidly because decomposition of the solute in the di-

\footnotetext{
${ }^{1}$ Eberhardt, Crawford, and Lipscomb, J. Chem. Phys. 22, 989 (1954).

${ }^{2}$ Hrostowski, Myers, and Pimentel, J. Chem. Phys. 20, 518 (1952).

${ }^{3}$ A. W. Laubengayer and R. Bottei, J. Am. Chem. Soc. 74, 1618 (1952)

"LeFevre, Dipole Moments (Methuen and Company, Ltd., London, 1948), p. 36.

${ }^{5}$ Weaver, Shore, and Parry, J. Chem. Phys. 29, 1 (1958).
}

electric cell produced a slow rise in the apparent dielectric constant value.

Measurements of the refractive index of the solutions were made with a Bausch and Lomb precision Abbe refractometer. No difficulty was encountered in obtain-

TABLE I.

\begin{tabular}{ccc}
\hline Mole fraction & $\begin{array}{c}\text { Dielectric constant } \\
\text { at } 25^{\circ} \mathrm{C}\end{array}$ & $n_{D^{25}}(5893)$ \\
\hline 0.000 & $2.274(6)$ & 1.4971 \\
0.024 & 2.277 & 1.4943 \\
0.044 & 2.278 & 1.4918 \\
0.088 & 2.286 & $\cdots$ \\
& & \\
\hline
\end{tabular}

ing reproducible readings before appreciable decomposition took place. In order to check the dispersion, the refractive index of several solutions was measured using light of three wavelengths. A plot of the refractive index for each solution against $1 / \lambda^{2}$ permitted evaluation of the index of refraction for light of infinite wavelength. A plot of $n_{\infty}$ against mole fraction permitted evaluation of $\left(\partial n_{\infty} / \partial x\right)_{0}$. Although this extrapolation is not quite linear, the precision of the measurements did not justify a more accurate extrapolation.

\section{RESULTS AND DISCUSSION}

Results of the dielectric constant and index of refraction measurements are shown in Tables I and II. The value of the dielectric constant of pure benzene was obtained from a Bureau of Standards publication ${ }^{6}$ and was used to calibrate the dielectric cell.

Because of the instability of the solutions, no attempt was made to obtain the time-consuming volume measurements necessary for determining the density of the solution. In order to calculate the apparent dipole moment, use was made of the extrapolation method of Cohen-Henriquez as given by Böttcher. ${ }^{7}$ In this method the "orientation polarization" is obtained directly from the dielectric constant and index of refraction measurements without use of the density. The equation used for the calculation was

$$
[P]_{d}=\left[3 M_{0} / d_{0}\left(e_{0}+2\right)^{2}\right]\left\{(\partial e / \partial x)_{0}-2\left(n_{\infty}\right)_{0}\left(\partial n_{\infty} / \partial x\right)_{0}\right\},
$$

${ }^{6}$ A. A. Maryott and E. R. Smith, "Table of dielectric constants of pure liquids," Natl. Bur. Standards Circ. No. 514 (1951).

${ }^{7}$ C. I. F. Böttcher, Theory of Electric Polarization (Elsevier Publishing Company, Amsterdam, 1952), p. 303. 
TABLE II.

\begin{tabular}{lllll}
\hline \multicolumn{5}{c}{ Refractive index } \\
\hline Mole fraction & $5893 \mathrm{~A}$ & $5461 \mathrm{~A}$ & $4358 \mathrm{~A}$ & $\lambda_{\infty}$ \\
\hline $\begin{array}{l}0.000 \\
0.036\end{array}$ & 1.4975 & 1.5015 & 1.5191 & 1.4716 \\
0.057 & 1.4933 & 1.4973 & 1.5146 & 1.4678 \\
$T=25^{\circ} \mathrm{C}$ & & 1.4949 & 1.5118 & 1.4653 \\
$M_{0}=78.1$ & $\partial n_{\infty} / \partial x=0.107 \pm 0.01$ & & \\
$d_{0}=0.879$ & & & \\
$e_{0}=2.274$ & $P_{d}=6.5 \pm 0.7 \mathrm{~cm}^{3}$ & & \\
$n_{\infty 0}=1.472$ & & & \\
\hline
\end{tabular}

where $[P]_{d}$ is the molar orientation polarization of the solute; $M_{0}, d_{0}$, and $e_{0}$ are the molecular weight, density, and dielectric constant of benzene; $n_{\infty 0}$ is the refractive index of benzene extrapolated to infinite wavelength; $x, e$, and $n$ are the mole fraction, dielectric constant, and index of refraction of the solution. This equation differs somewhat from the one given by Böttcher, having been obtained, not by neglecting the effect of the atomic polarization of the solvent, but by using Guggenheim's approximation ${ }^{8}$ that the atomic polarization of the solute and solvent are proportional to their partial molar volumes. Since there is no reliable way of estimating the atomic polarization of the solute, this would appear to be a reasonable approximation.

\section{ACKNOWLEDGMENTS}

The authors wish to express their sincere appreciation to the Chrysler Corporation for the heterodyne beat apparatus used in this investigation, and to the Wright Air Development Center for financial support. This work was conducted under Contract AF 33(616)-3343 with the U. S. Air Force, the sponsoring agency being the Aeronautical Research Laboratory of the Wright Air Development Center, Air Research and Development Command. The authors also wish to thank Dr. G. Kodama for his assistance in purification of $\mathrm{B}_{4} \mathrm{H}_{10}$.

\footnotetext{
${ }^{8}$ See reference 7, p. 305.
}

\title{
Internal Rotation and Infrared Spectra of Formic Acid Monomer and Normal Coordinate Treatment of Out-of-Plane Vibrations of Monomer, Dimer, and Polymer*
}

\author{
Tatsuo Miyazawa and Kenneth S. Pitzer \\ Department of Chemistry, University of California, Berkeley, California
}

(Received October 6, 1958)

\begin{abstract}
The infrared spectra of the four isotopic species of formic acid were measured in the vapor phase as well as in the solid nitrogen matrix in the region $400-800 \mathrm{~cm}^{-1}$. Absorption bands in the vapor phase were analyzed by considerations of band contours and comparisons with the frequencies distinctly observed in the matrix, and the previous assignment was revised. The torsional vibrations of the terminal OH groups of short chain polymers of $\mathrm{HCOOH}$ were observed in the matrix at 685 and $694 \mathrm{~cm}^{-1}$. The $\mathrm{OH}$ torsional frequencies of the trans isomer were located in the vapor phase at $582(\mathrm{HCOOH}), 576(\mathrm{DCOOH}), 450(\mathrm{HCOOD})$, and 448 $\mathrm{cm}^{-1}$ (DCOOD). The energy difference between the two isomers was determined to be $2.0 \pm 0.3 \mathrm{kcal} / \mathrm{mole}$. The potential hindering internal rotation was calculated to be $2 \mathrm{~V}(\mathrm{kcal} / \mathrm{mole})=2.1(1-\cos \theta)+9 .{ }_{.9}(1-\cos 2 \theta)$ $-0.1(1-\cos 3 \theta)$ from the energy difference and the fundamental torsional frequencies. The entropy of mixing of the two isomers was found to be $0.3 \pm 0.1 \mathrm{cal} \mathrm{deg}^{-1}$ mole $\mathrm{e}^{-1}$ at $25^{\circ} \mathrm{C}$. A normal coordinate treatment was made of the cis and trans isomers of monomer and of the dimer and polymer. The double bond characters calculated from the torsional potential constant agree with those calculated from bond lengths.
\end{abstract}

\section{INTRODUCTION}

$\mathbf{T}$ HE stable configuration of formic acid monomer has been known to be cis by studies of the infrared vibration-rotation spectra, ${ }^{1}$ microwave absorption, ${ }^{2}$ electron diffraction, ${ }^{3}$ and dielectric constant. ${ }^{4}$ The latter study ${ }^{4}$ has shown, however, that the effective moment of the monomer increases with temperature,

\footnotetext{
* This research was assisted by the American Petroleum Institute through Research Project 50.

1 V. Z. Williams, J. Chem. Phys. 15, 232, 243 (1947).

2 Lerner, Dailey, and Friend, J. Chem. Phys. 26, 680 (1957).

${ }^{3}$ I. L. Karle and J. Karle, J. Chem. Phys. 22, 43 (1954).

${ }^{4}$ Coop, Davidson, and Sutton, J. Chem. Phys. 6, 905 (1938).
}

suggesting an increase in mole fraction of the trans isomer at higher temperatures. Mariner and Bleakney have made an electron impact study and explained pairs of appearance potentials by postulating the coexistence of the cis and trans isomers. An infrared band of acetic acid monomer observed at $538 \mathrm{~cm}^{-1}$ has been assigned ${ }^{6}$ to the trans isomer; further work on acetic acid in this laboratory will be published soon.

The present study was undertaken to investigate the internal rotation of formic acid monomer. Infrared

\footnotetext{
${ }^{5}$ T. Mariner and W. Bleakney, Phys. Rev. 72, 792 (1947)

${ }^{\circ} \mathrm{W}$. Weltner, Jr., J. Am. Chem. Soc. 77, 3941 (1955).
} 